\title{
Fenitrothion Bio-Efficacy on Different Intradomicile Surface Types Against Anopheles (Nyssorhynchus) Albimanus in the Main Malaria Endemic Regions of Panama
}

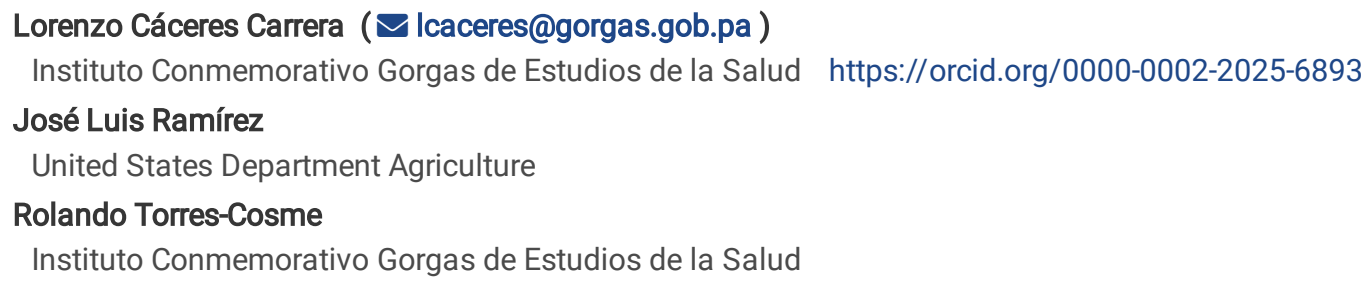

\section{Research}

Keywords: Anopheles (Nys.) albimanus, fenitrothion, bio-efficacy, susceptibility, resistance, spraying.

Posted Date: September 8th, 2020

DOI: https://doi.org/10.21203/rs.3.rs-70802/v1

License: (c) (i) This work is licensed under a Creative Commons Attribution 4.0 International License. Read Full License 


\section{Abstract}

Background: The use of intradomicile residual insecticide on a large scale is a proven and efficacious intervention against malaria mosquito vectors. The objective of the study was determined the bio-efficacy and resistance of fenitrothion insecticide against the mosquito $A n$. (Nyssorhynchus.) albimanus Wiedemann.

Methods: This study included seven communities located in different endemic regions where fenitrothion is used to control An. (Nys.) albimanus populations. The test of bio-efficacy and susceptibility were conducted following the WHO standard bioassay methodology.

Results: The average percent mortality of An. (Nys.) albimanus exposed to fenitrothion in the seven communities tested were $96 \%$ and $92 \%$ for the first two months. This bio-efficacy was maintained until the fifth month with $81 \%$ mortality in communities with high IRS coverage. Anopheles (Nys.) albimanus was susceptible to the organophosphate insecticides fenitrothion and malathion, as well as to carbamate Propoxur but resistant to pirimiphos-methyl and chlorpyrifos.

Conclusion: This study demonstrates that fenitrothion maintains an elevated insecticide residuality and toxic effect on different types of surfaces until the fifth month post-application. Furthermore, An. (Nys.) albimanus remains highly susceptible to this insecticide, providing a high degree of protection against mosquito bites inside households, and interrupting malaria transmission in places with high IRS coverage and where the mosquito is still susceptible to fenitrothion application.

\section{Introduction}

Malaria is a parasitic disease that in addition to its direct health impact, it also imposes a significant economic burden to communities through work days and school days lost to the disease, and the reduction of economic productivity [1]. In the last 15 years, a concerted effort to control this disease has led to a $1 / 3$ reduction in the number of cases and a $60 \%$ reduction in the number of deaths around the world [2]. This could be attributed to control intervention measures such as the use of long-lasting insecticidal-treated nets (LLINs), indoor residual insecticide spraying (IRS), use of rapid-diagnostic tests (RDTs), and the combined therapies based on artemisinin (ACTs), which have become efficacious in the fight against malaria [3]. During the last few years, malaria endemic countries have implemented an efficacious vector control using two available tools in separate or in combination. In such cases, the use of IRS and LLINs together with the treatment of malaria cases using ACTs (guided via definitive diagnostics) have led to a significant reduction in the morbidity and mortality associated to malaria [45]. A review of previous interventions has suggested that this strategy could reduce the number of malaria cases in $39 \%-62 \%$ and infant mortality by $14-29 \%[6]$. Furthermore, it has been demonstrated that IRS significantly interrupts malaria transmission, eliminates malaria vectors and reduces malaria incidence [7].

The first use of DDT (Dichloro diphenyl trichloroethane) as a control measure against anopheline vectors through IRS were conducted by Harold Trapido at the Gorgas Memorial Laboratory between 1944-1946. These studies showed a dramatic reduction in the population of An. (Nyssorhynchus) albimanus Wiedemann and malaria incidence in the communities where they were applied [8-9]. The discovery of efficacious synthetic insecticides with residual action to control malaria led to an intensive use of indoor spray as a main control measure towards the second half of the $20^{\text {th }}$ century [10-11]. Later, it was incorporated as an important strategy against malaria around the world [12-13]. The standard application method for insecticides with residual action was perfected for the application of DDT using a mixture of water and powder on mud or clay surfaces and thatched roofs that were common in the past century $[8,14]$. This method was later adapted by the World Health Organization (WHO) as the main tool for the control of malaria anopheline vectors. This was also a critical component of the Global Malaria Eradication Program (GMEP) from 1955-1969 and the main intervention that contributed to the elimination or dramatic reduction of malaria in parts of Europe, Asia and Latin America [7]. Since then, the IRS has continued to represent the most utilized method to control malaria vectors $[13,15-16]$.

Considering the progress made against malaria during the last decades [17-18], the effort has moved from control to elimination in many parts of the world [17,19]. Malaria elimination was established as a final objective of WHO and the Roll Back Malaria alliance (RBM) [20], and after a 40-year lapse, malaria elimination is back on the world health agenda. Malaria incidence has been reduced in $50 \%$ in a number of endemic countries in the last two decades [21]. The malaria incidence rate decreased around the world between 2010 and 2018 from 71 to 57 cases per 1000 inhabitants. In addition, there were 228 million malaria cases and 405,000 deaths registered around the world in 2018 [22].

According to Pan American Health Organization (PAHO), the Americas have experienced an increase in the total number of cases due to a rise, since 2015, in the number of cases in Venezuela, and to a transmission increase in endemic areas in countries such as Brazil, Colombia, Guyana, Nicaragua and Panama. Furthermore, there has been outbreaks in countries that previously made advancements towards malaria elimination (Costa Rica, Dominican Republic and Ecuador). In comparison, Paraguay and Argentina have received certification as malaria-free countries in July 2018 and May 2019, respectively. Also, worth mentioning are El Salvador and Belize, countries that have presented no autochthonous cases since 2017 and 2019, respectively [23]. 
The use of IRS and LLINS alone or in combination for the control of malaria vectors is done based on the proven efficacy of its use as an antimalarial strategy, taken into consideration the existing epidemiological conditions and the logistic requirements associated to its use [2425]. The strategies currently using IRS are particularly appropriate for a rapid control of transmission, but they require a good organization and community reception [26]. Insecticide bio-efficacy will also depend on the behavior of the local mosquito population [27] and their susceptibility to the insecticides used on the LLINs or IRS [28]. Currently, the technological advancement made on the coatings used on insecticide treated surfaces offers a novel use of insecticides that is much more residual than the IRS and requires a limited change in strategy [29-30].

Currently there are only two insecticide classes available for the control of malaria, the carbamates and organophosphates, which have a different mode of action in case resistance to insecticidal pyrethroids is developed [31]. The WHO Pesticide Evaluation Scheme (WHOPES) is the entity in charge of approving the use of insecticides in indoor sprays, among them carbamate bendiocarb and the organophosphates pirimiphos-methyl and fenitrothion [32-33]. Their mode of action is different from those of pyrethroids and DDT, in that they are cholinesterase inhibitors [34]; and could be used in combination in case of a detection of pyrethroid insecticide resistance [35]. The organophosphate and carbamate insecticides are efficacious against insecticide-resistant mosquitoes when they are used via IRS or on wall-treatments [31,36]. Nevertheless, there exist resistance to organophosphates and carbamates due to the insensitivity to acetylcholinesterase (Achel) that has been reported in some populations of mosquito vectors [37-38]. The malaria vector control programs have encountered multiples problems with resistance that could potentially paralyze the strategies until a new insecticidal molecule is found and is available for their use [39]. Several IRS products are currently available and several are being evaluated by WHO. The products currently available are (i) Actellic ${ }^{\circledR} 300$ CS (Syngenta), a formulation of microcapsules of pirimiphos-methyl (an organophosphate) and (ii) SumiShield® 50 WG (Sumitomo Chemical), a new product that contains clothianidin (a neonicotinoid) [40]. With few alternatives available, as far as insecticide use for the control of malaria is concerned, it is necessary that we conduct regular studies to determine the bio-efficacy and susceptibility of the insecticides being used.

The residuality time and bio-efficacy of the majority of insecticides are affected by the chemical nature of the surfaces where they are applied [41]. Thus, these two parameters can vary depending on the materials used to construct the homes in the rural, poor and indigenous communities [42]. A correct application of the insecticide should maintain its bio-efficacy and residuality on the applied surfaces for a significant period of time, to ensure mosquitoes receive a lethal dose when in contact with the treated surfaces [43]. Furthermore, the insecticide toxicity should be maintained during a sufficient period of time to avoid frequent applications which can be a time consuming and economically costly strategy [42].

In Panama, malaria continues to represent a significant health problem due to its incidence and great economic impact with endemic/epidemic transmission rates that have been maintained an average of 694 diagnostic cases annually in the last seven years (20112017). During this period, an annual parasitic incidence of $0.2 / 1,000$ inhabitants, with a morbidity rate of $17.9 / 100,000$ inhabitants, and two deaths were observed. About $98.6 \%$ of cases were due to Plasmodium vivax infection. More than $85 \%$ of malaria cases occur in the indigenous regions, which occupy $22 \%$ of the Panamanian territory and where only $12 \%$ of the total Panamanian resides [44]. These endemic zones are located along the borders with Costa Rica and Colombia [45]. In the fight against malaria the National Malaria Program (NMP) from the Health Ministry (MINSA) continues to utilize a strategy based on the active and passive search of suspected cases and through the use of insecticides with indoor residual activity, to prevent and control malaria transmission.

The use of insecticidal spray with residual activity is the main tool used to control anopheline vectors by the NMP. Its use is conducted with regularity with determined doses for the type of insecticide used. In the case of fenitrothion the dosage is $2 \mathrm{~g} / \mathrm{m}^{2}$ and its application is conducted every 3-6 months [46]. It is of great importance to know the duration of bioactivity and bio-efficacy of this insecticide after each application to have an effective control of the anopheline vectors. In this study we provide important technical information about the minimum interval time required between each application. This is an important factor needed to maintain the bio-efficacy and susceptibility of insecticides. The objective of this study was to determine the efficacy and susceptibility of the insecticide fenitrothion when applied to diverse surfaces in an effort to control An. (Nys.) albimanus mosquitoes.

\section{Materials And Methods}

Site of collection: Historically, An. Albimanus populations have been subjected to the selective pressure of insecticides applied by the NMP (Figure 1). The NMP from MINSA, considered the magnitude of the malaria problem and the need to determine the efficacy of indoor residual spray and the susceptibility of An. (Nys.) albimanus to the insecticide fenitrothion. This insecticide is commonly used in the main malaria endemic regions of Panama. For this study seven communities were selected from three Panamanian regions that historically have maintained active malaria transmissions and frequent insecticide applications. The localization of the selected sites are indicated in Figure 2. The geographical coordinates and epidemiological information (malaria cases) are in turn presented in Table 1. 
- Sumithion ${ }^{\circledR} 40$ \% WP: 0,0-dimethyl O-(4-nitro-m-tolyl) phosphorothioate. Sumitomo Chimical Co., Ltd.

- Fenitrothion: 0,o-dimethyl 0-(4-nitro-m-tolyl) phosphorothioate; 98,5\% purity, made by Sumitomo Chemical Company.

- Malathion: S-1,2-bis(ethoxycarbonyl)ethyl 0,0-dimethyl phosphorodithioate; 97,0 \% purity, from the American Cyanamid Co., Princeton, New Jersey.

- Chlorpyriphos: 0,0-diethyl 0-3,5,6-trichloro-2-pyridyl phosphorothioate; 94,0 \% purity, by Dow Chemical Co., Midlan, Michigan.

- Pirimiphos-methyl: 0-2-diethylamino-6-methylpyrimidin-4-yl-0,0dimethyl phosphorothioate; 99,8 \% purity made by Syngenta.

Mosquito strain used in bioassays: To conduct the wall susceptibility bioassays, we used females from the field strain of An. (Nys.) albimanus collected in the community of Aguas Claras, from the indigenous comarca Madungandi. This place has similar environmental/ecological characteristics and insecticide application regime similar to those sites selected in this study. The An. (Nys.) albimanus strain was colonized and maintained in the lab under laboratory conditions with a minimum average temperature of $28.5^{\circ} \mathrm{C}(\mathrm{DE}: 0.5703)$ and maximum of $30^{\circ} \mathrm{C}$ and relative humidity of 70 to $80 \%$ (DE: 0.3939 ) and a photoperiod of $12: 12$ (day/night).

Selected dwellings: The houses were selected randomly. Dwellings were built from diverse materials but predominantly contained unpainted wood, painted wood, bamboo, tree trunks and palm bark. This presented a unique opportunity to evaluate the effect of each type of surface available and the insecticide fenitrothion persistence along a period of time. Other factors considered for the selection of houses included the accessibility and the owner's consent [47]. In addition, the inhabitants were adviced to not alter the treated surfaces (i.e. through washing).

Insecticide Application: We used the concentration recommended by WHO for fenitrothion: $2.0 \mathrm{~g} / \mathrm{m}^{2}$. The spray technique consisted in using 10 liter standard sprinkler X-Pert Hudson ${ }^{\oplus}$ with a 8002 nozzle that makes a drop of $100-400 \mu$ of diameter. The distance from the nozzle to the wall was maintained at $45 \mathrm{~cm}$ and the insecticide was applied in vertical bands from the ceiling to a height of $3 \mathrm{~m}$ and up to $30.5 \mathrm{~cm}$. above the floor. The vertical bands were $75 \mathrm{~cm}$ wide for the first application and $70 \mathrm{~cm}$ for subsequent bands, superimposing $5 \mathrm{~cm}$ with the previous band. The sprinkle pressure used was of $25-55$ pounds $/$ inch $^{2}$, a velocity of $5 \mathrm{sec} / \mathrm{m}^{2}$ and an approximate discharge of $757 \mathrm{ml} / \mathrm{min}[33,48]$. The spraying application was conducted by technical personnel from the NMP under supervision of the squad leader and following the WHO standardized protocols for application of residual insecticides (Fig.2).

Wall bioassays: The evaluation of fenitrothion efficacy and residual activity on diverse treated surfaces was monitored monthly following the WHO standardized protocols [33]. We used batches of 10 female An. (Nys.) albimanus mosquitoes (Aguas Claras strain) that were 2-4 days old and blood fed with Cavia porcellus blood. The bioassays were conducted one-hour post-blood feeding. The mosquitoes were placed inside polyethylene cones fixed firmly on the walls and exposed to the intradomicile surfaces for about 30 minutes. We selected 10 houses for each bio-efficacy test. The exposition cones were placed in selected places inside the bedroom and living room of each of the houses. Following the exposure period, each mosquito batch was transferred to previously labeled clean containers with a $10 \%$ sugar-moistened cotton ball.

Mortality was observed at 24 hour post-exposure (Fig. 3). The periodical evaluation of fenitrothion bio-efficacy was conducted in months 1,2 , $3,4,5,6,7$ and 8 post pesticide applications. Each efficacy test used 30 exposure cones, while control groups used 10 batches of mosquitoes that were exposed to untreated surfaces.

Susceptibility bioassays: The susceptibility to insecticides was determined via susceptibility test with adult An. (Nys.) albimanus females (Aguas Claras strain) from the first generation (F1) exposed to insecticide impregnated papers containing the organophosphate fenitrothion $(1 \%)$, malathion ( $5 \%)$, chlorpyrifos $(0.4 \%)$, pirimiphos-methyl $(0.25 \%)$ and the carbamate propoxur $(0.1 \%)$, following the dosage and exposure time according to WHO's standard protocols [49]. The bioassays used females that were $3-5$ days old in batches of 25 mosquitoes that have been previously maintained on a sugar solution. The average temperature registered during the bioassays was of $27 \pm 2{ }^{\circ} \mathrm{C}$ and $70-80 \%$ relative humidity. The mosquitoes were transferred to clean containers following the exposure time and provided with $10 \%$ sugar ad-libitum. Each insecticide bioassay was replicated five times along with its respective controls.

Analysis: The percent mortality to determine the indoor spray bio-efficacy was calculated and analyzed according to the WHO criteria. The IRS is considered efficacious when the mortality percentage in the exposed mosquitoes is $₫ 80 \%$ [30]. In our susceptibility assays the mortality rate values were assessed at 24 hour post-exposure. The analysis of resistance and susceptibility was also conducted according to the standards provided by WHO guidelines. A percentage between $98-100 \%$ is considered susceptible and mortality below $98 \%$ suggest the existence of resistance. Furthermore, if the mortality rate is between $90-97 \%$ it suggests the presence of resistant genes and should be confirmed with additional tests. If the mortality is below $90 \%$, it confirms the existence of resistance genes [49]. We used Abbott's formula to correct the mortality of the exposed mosquitoes when the mortality in the control group oscillated between $5-20 \%$ [50].

Ethical considerations: All the household heads from the selected dwellings were informed of the study before its initiation. This study was conducted with collaboration and participation of the vector control technical personnel from NMP, MINSA, Panama. 


\section{Results}

The wall bioassays performed to evaluate the bio-efficacy of fenitrothion PW at $40 \%$ were conducted during the months of January-November 2017. The coverage percentage during the treatment cycles in the communities were between 60 and $100 \%$. The indigenous communities registered a lower coverage (40\%), due to the Guna cultural practices and the lack of information about the importance of IRS in interrupting malaria transmission. The application in non-indigenous communities reached a coverage of $100 \%$.

A total of 16,800 An. (Nys.) albimanus Aguas Claras mosquito strain were used in the wall bioassays, while 2,500 mosquitoes were used in the susceptibility bioassays. The bioassays were conducted at a minimum temperature of $28.5^{\circ} \mathrm{C}$ and maximum of $30^{\circ} \mathrm{C}$ and with a minimum relative humidity of $70 \%$ and maximum of $80 \%$.

Table 2 depicts the variation in fenitrothion bio-efficacy and residuality between one and nine months. We observed a decrease in the insecticidal bio-efficacy on the different surfaces tested as time elapsed. The first month post-treatment showed a fenitrothion bio-efficacy between 93.4 to $98 \%$ in all the treated surfaces, with an average mortality of $90.1 \%$ and a median of $90.3 \%$. Between the third and fifth month the bio-efficacy was maintained at $\geq 80 \%$ mortality, with an average mortality of $82.4 \%$ and a median mortality of $82.6 \%$ there was a progressive loss of bio-efficacy between the sixth and eight months of application. Thus, fenitrothion maintained its bio-efficacy as an IRS up to the fifth month post-application. The control groups showed a mortality rate between one and two percent. As was expected, the fenitrothion bio-efficacy varied as time elapsed, showing lower bio-efficacy and residuality on Gira palm and bamboo (Fig. 4).

The bioassay results presented in Table 3 show the An. (Nys.) albimanus susceptibility following exposure to the organophosphate pesticides fenitrothion and malathion. No significant differences were obtained in the mortality rate in these bioassays. However, An. (Nys.) albimanus resulted being resistant to the organophosphate pesticides pirimiphos-methyl and chlorpyriphos according to WHO standards. Nevertheless, despite being resistant, the mortality rate was elevated (above WHO's 90\% mortality rate threshold). In contrast, An. (Nys.) albimanus mosquitoes exposed to the insecticide carbamate propoxur were susceptible with a $98.2 \%$ mortality rate.

\section{Discussion}

The rise in insecticide resistance in Anopheles mosquitoes in the Americas represent a rising challenge to the control and elimination of malaria [51-53]. Although there are several insecticides with residual action available for indoor spraying, some of these have become ineffective due to the development of resistance, while others, although still effective, are no longer accepted due to its high toxicity towards mammals or their dangerous persistence in the environment [41]. Notwithstanding the fact that 57 Anopheles mosquito species have developed some level of resistance, IRS still continues to be the main method used to control vectors in many malaria endemic countries [5455]. From the start of the NMP in Panama, a diverse set of organochlorines, organophosphates, carbamates and pyrethroid insecticides have been used; creating a selective pressure against the An. (Nys.) albimanus populations [56]. The NMP, similar to other malaria programs around the world, uses as the first line of defense the application of IRS against anopheline mosquito vectors. This approach has contributed, to a certain extent, to the reduction of malaria transmission in Panama (46). With the regional commitment as an initiative to eliminate malaria, the NMP has decided to conduct tests to detect possible failures in the current control methods and in that way improve the prevention strategies. Among these tests are the determination of bio-efficacy and resistance to insecticides (with indoor residual action) in the main malaria endemic regions of Panama.

The results of this study indicate that the quality of insecticide spraying and the nature of the different surfaces or walls in the seven selected communities have an effect on the toxicity and residuality of fenitrothion. Most of the houses in these communities have zinc plates for roofs and unpainted wooden walls. In comparison, the houses from the Guna indigenous communities followed their cultural tradition and were built with palm leaf roofs, walls made from small woody tree trunks placed vertically, without windows and dirt floors [57]. Our study assayed diverse surfaces such as painted wood, unpainted wood, bamboo, Gira palm and tree trunks. Our results show that smooth surfaces do not absorb large quantities of insecticide particles and resulted in the longer duration of fenitrothion toxicity and residual effect. In comparison, porous surfaces that absorb a large quantity of insecticide had a shorter duration of toxicity and residuality. In this case, smooth surfaces such as painted wood and unpainted wood maintained the greatest insecticide toxicity and the longest residuality. Meanwhile, surfaces such as Gira palm, bamboo and tree trunks, which presented more porosity and absorption lost its toxicity and residuality in a short period of time. This effect has been previously observed, with the chemical nature of surfaces affecting the residuality and efficacy of most insecticides [41]. Thus, the persistence and bio-efficacy of insecticides can vary depending on the type of surfaces and materials that are used to build a house in the rural and economically poor indigenous regions [42].

In similar studies, the application of deltamethrin on different types of surfaces, among them wood, bamboo and brick, found that the smooth surface of a bamboo presented the longest duration of insecticide toxicity and residuality. On the contrary, the rapid absorption by the brick porous surfaces led to a much faster loss of deltamethrin activity [58]. Several other studies have also found similar results with insecticides 
losing their toxicity much faster on porous surfaces than on smooth surfaces such as wood panels, and ceramic tiles [59-60]. The duration of bio-efficacy should be within the residuality range found in previous studies or according to WHO recommendations. Nevertheless, in some places the residuality can vary from 2-10 months depending on the kind of treated surfaces [61]. Thus, the residual efficacy of the IRS can vary according to the type of wall construction and the quality of insecticide spray application [58,62]. Furthermore, the IRS effectiveness depends on the level of resistance of the main malaria vectors and the insecticide residuality time on the treated surfaces [62]. An application of low quality can contribute to the development of insecticide resistance, an additional burden to the malaria control strategies [63]. If the residual activity is shorter than expected, it can also contribute to an increase in the malaria incidence where the period of malaria transmission exceeds the insecticidal residual effect [64]. The indoor residual spray has demonstrated that it can have an epidemiological impact through the reduction of malaria transmission. This is especially true if the applied insecticide on different surfaces, and with a large cover area per locality/ transmission area, leads to high mortality rates in the anopheline vector population [65].

In this study we also found that the bio-efficacy depends on the formulation of the applied insecticide, mosquito species susceptibility, the study area, type of treated surface, humidity and temperature. A sustained evaluation of the bio-efficacy of insecticides used in IRS can provide critical technical information on the efficacy against a specific mosquito species, their safety to the exposed human inhabitants, the sprayers and in the methods of insecticide application [66]. According to the recommendations provided by WHO [49], an ideal insecticide should have a minimum residual effect on mosquito mortality equal to or greater than $80 \%$ at $24 \mathrm{~h}$ post-exposure.

This research provides the NMP with important evidence and technical information on the fenitrothion bio-efficacy against the main malaria vector, An. (Nys.) albimanus (45). In this study the effectiveness of fenitrothion residuality lasted for 20 weeks; primarily on two types of walls, and decreasing with time on the different surfaces until registering a low mortality/bio-efficacy on the eight month. Nevertheless, this insecticide can only be effective in areas where the An. (Nys.) albimanus is still susceptible, with potential variation or reduction in the susceptibility over time. Thus, our results fall within the recommended WHO guidelines [67]. Nevertheless, additional studies are needed to learn the biting behavior and resting, population density of the different mosquito species and the bioecological characterization to better pinpoint the entomological impact of fenitrothion indoor spray application. This study presented some limitations. For instance, it utilized a study design that covered a limited period of time in each of the selected localities and the absence of a control locality that were to be evaluated at the same time. Thus, we should be careful to make causal inferences on the quantitative impact of the intervention. In addition, other factors, not evaluated in this study, might be related to the transmission reduction, such as the environmental factors associated with transmission intensity such as climate, human behavior and other methods of control [68].

Furthermore, it is necessary that the NMP evaluates alternative insecticides to be used at the time when a decrease in fenitrothion bio-efficacy is observed. The selection of an alternative insecticide with residual action must depend on An. (Nys.) albimanus susceptibility, the half-life of residual action, safety to humans, other animals and the environment. A technical factor of importance to malaria control programs is to determine the period of insecticide toxicity duration and residuality that leads to high mortality, given that this information will allow the development of programs, plans and logistics to determine spray cycles and coverage of the human population that will be protected until the next application cycle. An insecticide with high bio-efficacy leads to a protection against the bite of mosquitoes decreasing the risks of transmission, and in combinations with other strategies lead to a prevention of epidemic outbreaks. Previous studies have indicated that the insecticide bio-efficacy of residual action is very efficient in regions where the vector is completely susceptible to the insecticide applied [30].

One of the objectives of this study was to determine the level of insecticide resistance in An. (Nys.) albimanus mosquitoes. The mosquitoes used in the susceptibility assays originated from one of the main malaria endemic regions of Panama with characteristics that resembles that of the other selected locations in this study. The susceptibility bioassays indicated that An. (Nys.) albimanus continue to be susceptible to the organophosphate insecticide fenitrothion, carbamate propoxur and malathion. We observed that the level of susceptibility for fenitrothion was greater than for the insecticides malathion and propoxur. Nevertheless, the differences in the mortality rates were not statistically significant. This indicates that, despite the re-introduction of fenitrothion in 2002 for its use in IRS, the mosquito populations have not yet developed insecticide resistance. The results from this work coincide with work conducted with other native populations of An. (Nys.) albimanus from three malaria endemic communities (Pintupo, Aguas Claras and Puente Bayano), and in which they are susceptible to the insecticides organophosphate fenitrothion, malathion, chlorpyrifos and to carbamate propoxur. However, they had resistance to pyrethroids, deltamethrin, lambdacyhalothrin, cyfluthrin and cypermethrin [44]. These levels of insecticide resistance can contribute to failures in malaria control and lead to a greater malaria transmission [69].

The susceptibility of An. (Nys.) albimanus to fenitrothion could be due to the moderate frequency of application and to the percentage coverage. Given that malaria in endemic regions is characterized by transmission in small outbreaks or focus [45,70], the IRS applications do not cover all the communities in a specific malaria endemic area or the entire community where the outbreak is currently happening.

Furthermore, there is reluctance on the part of homeowners to accept the IRS application especially among indigenous communities. Thus, in general, there is a partial application that does not attain $100 \%$ coverage of the houses and communities. This would leave a mosquito 
population free from exposure to the insecticide and allow these mosquitoes to maintain fenitrothion susceptibility within the population of An. (Nys.) albimanus that is targeted.

Another aspect that should be considered is the biting and resting behavior of the mosquito when affronting the selective pressure of the insecticides applied to surfaces. We have to consider that the socio-environmental changes such as the introduction of effective vector control tools could in turn induce a change in the behavior of Anopheles mosquitoes. Within the context of malaria control, the use of physical barriers (nets on windows and doors) as well as the insecticide action, induce a stress in anopheline mosquitoes interfering with blood feeding or with resting on interior walls until their eggs are fully matured. Studies indicate that behavioral modifications could include a change in feeding times, a switch from feeding exclusively on humans to feeding on other animals or an increase in the exophilic behavior [71]. These behavioral changes could rise due to selection pressure induced by LLINs and IRS and lead to mosquito vectors feeding at earlier times and/or in the peridomicile or extra-domiciles. This could in turn give them a selective advantage giving rise to a phenotypic change in the population [72-73].

Despite the results that indicate fenitrothion susceptible in An. (Nys.) albimanus mosquitoes, the NMP should maintain a constant monitoring and surveillance evaluating the bio efficacy and susceptibility in the mosquito populations that are subjected to selective pressure with fenitrothion. In a similar work conducted in the Yucatan Peninsula, Mexico, the mosquito An. (Nys.) albimanus was resistant to DDT and deltamethrin, but was susceptible to carbamate bendiocarb and to the organophosphate pirimiphos methyl, with the exception of a locality (La Union) who was pirimiphos methyl-resistant [53]. It is important to note that the NMP of Panama, does not have program or technical personnel trained in each of the malaria endemic regions that would routinely monitor and conduct surveillance work on the bio efficacy and insecticide-resistance of anopheline mosquitoes. This risks the usefulness of the insecticides currently being used to control mosquito vectors. The early detection of susceptibility changes in mosquitoes is of great importance to the vector control programs to maintain the effectiveness of current insecticides. Because surveillance and monitoring work on insecticide resistance is limited in Panama, the level of susceptibility is not known locally in the communities with active malaria transmission in the different endemic regions. In general, the magnitude of the problem of insecticide resistance is unknown for most of the malaria endemic regions in Panama [74]. The development and implementation of a monitoring program of insecticide resistance by the NMP, is critical to maintain an effective strategy in the fight against An. (Nys.) albimanus. There is a need for finding the basal level of insecticide resistance for all the mosquito vectors in all the malaria endemic regions of Panama. The absence of this information puts at risk the usefulness of insecticides that are currently being used to control mosquito vectors. Furthermore, this information provides crucial technical information that allows us to apply strategies to prevent or delay the development of resistance, while maintaining an effective malaria control.

An important limitation in this study is that we could only work with one field-derived strain from one of the four endemic region of Panama. However, at the moment of strain selection, we made the effort to select a region with similar ecological, environmental and selective pressure than the sites selected for the bio-efficacy work. Thus, additional studies are needed to follow and select additional sites that would allow us to determine the bio-efficacy and susceptibility of the applied insecticides against An. (Nys.) albimanus.

In conclusion, this study shows that fenitrothion maintains an elevated residuality and toxicity in different types of surfaces, with An. (Nys.) albimanus remaining susceptible to this insecticide. This leads to an increased protection against mosquito bites inside the houseand can contribute to the interruption of malaria transmission in places that maintain a high IRS percentage coverage. This could also allow the maintenance of fenitrothion susceptibility in An. (Nys.)albimanus. Furthermore, this study provides important technical information valuable to the NMP efforts at controlling this important malaria vector. Here we present a base line of fenitrothion insecticide susceptibility and those alternative insecticides that could be used at a time when an insecticide change is needed. Furthermore, we provide a detailed map of the areas with An. (Nys.) albimanus populations that are susceptible or resistant to insecticides. This information could be further used by the NMP to considerably diminish the modifications often conducted in the use of insecticides, reduce the number of control strategy changes and reduce the cost of vector control programs. Our study also recommends that the NMP develop and implement a program that routinely monitors the bio-efficacy and insecticide-resistance to attain an adequate management of insecticide resistance when this technical problem eventually arises.

\section{List Of Abbreviations}

WHO: World Health Organization, NMP: National Malaria Program, MINSA: Ministerio de Salud, ICGES: Instituto Conmemorativo Gorgas de Estudios de la Salud, GMEP: Global Malaria Eradication Program,WHOPES. WHO Pesticide Evaluation Scheme, EMMIE: Elimination of Malaria in Mesoamerica and the Island of Hispaniola, DDT: Dichloro diphenyl trichloroethane, Achel: Acetylcholinesterase inhibitor, LLINs: Long lasting insecticidal nets, IRS: Indoor residual spraying, RDTs: Rapid diagnostic tests, ACTs: Artemisinin-based combination therapies, AIDS:Acquired immunodeficiency syndrome.

\section{Declarations}


Ethics approval and consent to participate: This research study is a concerted effort with the consent, approval and participation from authorities, the technical and professional personnel and scientific researches from MINSA and ICGES. Samples and human data were not used.

Consent for publication: Not applicable. Availability of data and materials. The data sets analyzed during the current study are available from the corresponding author on reasonable request.

Availability of data and materials: The data sets analyzed during the current study are available from the corresponding author on reasonable request.

Competing interests: The authors declare that they have no competing interests. LC is member of the Sistema Nacional de Investigación (SNI), SENACYT, Panama. Any opinions, findings, conclusions or recommendations expressed in this publication are those of the author(s) and do not necessarily reflect the view of the U.S. Department of Agriculture. The mention of firm names or trade products does not imply that they are endorsed or recommended by the U.S. Department of Agriculture over other firms or similar products not mentioned; the USDA is an equal opportunity employer.

Funding: This research was funded by the Ministry of Economy and Finance of Panama (MEF), Project No. 009044.052. The MEF was not involved in the design of the study, collection, analysis, interpretation of data and in writing the manuscript.

Authors' contributions: LCC conceived and designed the project, funding acquisition and project management, participated in field and laboratory work as well as in the development of this study, analyzed data and interpreted the results, drafted the first version of the manuscript and final revision of the manuscript. RT-C participated in laboratory and field work, analyzed data and interpreted the results as well as reviewed the manuscript. LCC, JLR and RT-C participated in data analysis, result interpretation and writing the manuscript. All the authors read, contributed and approved the final manuscript.

Acknowledgements: We would like to thank Fernando Vizcaíno, Director of the Department of Vector Control from the Ministry of Health; Carlos Victoria, Director of the National Malaria Program; regional coordinators of vector control; technicians Santos Vega, Darien Health Region; Jose De Leon, Bocas del Toro Health Region; Cipriano Ayarza, Guna Yala Health Region; Santiago Cherigo, Panama Este Health Region; and all the operative personnel that collaborated and supported the development of this research.

\section{Authors' information:}

Lorenzo Caceres Carrera PhD. Department of Medical Entomology, Gorgas Memorial Institute of Health Studies, Panama City, Panama. Email: lcaceres@gorgas.gob.pa

Jose L Ramirez PhD. Crop Bioprotection Research Unit, National Center for Agricultural Utilization Research, Agricultural Research Service, United States Department of Agriculture, Peoria, Illinois, USA. Email: Jose.Ramirez2@usda.gov

Rolando Torres-Cosme MSc. Department of Medical Entomology, Gorgas Memorial Institute of Health Studies, Panama City, Panama. Email: rtorres@gorgas.gob.pa

\section{References}

1. Sachs J\& Malaney P. The economic and social burden of malaria. Nature. 2002; 415(6872): 680-5. doi: 10.1038/415680a.

2. World Health Organization. World Malaria Report 2015. World Health Organization. Geneva, Switzerland. Available online:http://apps.who.int/iris/bitstream/10665/200018/1/9789241565158_eng.pdf?ua=1. Accessed 7 June 2019.

3. Okiro EA, Alegana VA, Noor AM, Snow RW. Changing malaria intervention coverage, transmission and hospitalization in Kenya. Malaria J. 2010; 9:285. doi: 10.1186/1475-2875-9-285.

4. World Health Organization. Global Malaria Programme. World Malaria Report 2013. World Health Organization. Geneva, Available online: http://www.who.int/malaria/publications/world_malaria_report_2013/report/en/. Accessed 18 January 2020.

5. Kleinschmidt I, Schwabe C, Benavente L, Torrez M, Ridl FC, Segura JL, Ehmer P, Nchama GN. Marked increase in child survival after four years of intensive malaria control. Am J Top Med Hyg. 2009; 80(6):882-8 DOI: https://doi.org/10.4269/ajtmh.2009.80.882.

6. Lengeler $\mathbf{C}$. Insecticide-treated bed nets and curtains for preventing malaria. Cochrane Database Syst Rev. 2004; (2):CD000363. doi: 10.1002/14651858.CD000363.

7. Pluess B, Tanser FC, Lengeler C, Sharp BL. Indoor residual spraying for preventing malaria. Cochrane database of Syst Rev. 2010; 14; (4):CD006657. doi: 10.1002/14651858.CD006657. 
8. Trapido, $\mathrm{H}$. The residual of dwellings with DDT in the control of malaria Transmission in Panama, with special reference to Anopheles albimanus. Amer J Trop Medicine. 1946; 26:383-415. DOI: https://doi.org/10.4269/ajtmh.1946.s1-26.383.

9. Trapido, $\mathbf{H}$. The development of a sprayer for use with water suspensions of DDT in Rural areas of Latin America. Amer J Tropical Medicine 1948; 28:721-39. doi: 10.4269/ajtmh.1948.s1-28.721.

10. Dixon DS. Paludrin (Proguanil) as a malaria prophylactic amongst African labour in Kenya. East Afr Med J. 1950; 27:127-30.

11. Roberts JMD. The control of epidemic malaria in the highlands of Western Kenya. Part II the Campaign. J Trop Med Hyg. 1964; 67:161-8.

12. World Health Organization. WHO expert committee on malaria, Twentieth report. Word Health Organization. Technical Report Series 2000; 892. Geneva. Available online: https://apps.who.int/iris/bitstream/handle/10665/42247/WHO_TRS_892.pdf?sequence=1\&isAllowed=y. Accessed 17 May 2020.

13. World Health Organization. Indoor Residual Spraying. Use of indoor residual spraying for scaling up global malaria control and elimination. 2006. Document: WHO/HTM/MAL/2006.1112. Available online: https://apps.who.int/iris/bitstream/handle/10665/69386/WHO_HTM_MAL_2006.1112_eng.pdf?sequence=1\&isAllowed=y. Accessed 20 June 2020.

14. Macdonald G. The Epidemiology and Control of Malaria. 1957. Oxford Univ. Press, London.

15. World Health Organization. Expert committee report on malaria, Twentieth report. Word Health Organization, Geneva. Available online: http://malaria.who.int/docs/ecr20_toc.htm. Accessed 20 November 2019.

16. Najera JA and Zaim M. Malaria vector control: Decision making criteria and procedures for judicious use of insecticides. 2002. WHO/CDS/WHOPES/2002.5, WHO, Geneva. Available online: who.int/ctd/whopes/docs/judiciousUseRev.pdf. Accessed 13 October 2019.

17. World Health Organization. Global malaria control and elimination: Report of a technical review. 2008; Geneva, Switzerland. 45 pag. Available online: https://apps.who.int/iris/bitstream/handle/10665/43903/9789241596756_eng.pdf?sequence=1. Accessed 20 September 2019.

18. World Health Organization. Malaria Report 2009. World Health Organization. Geneva, Switzerland. 66 pag. Available online: https://www.who.int/malaria/publications/atoz/9789241563901/en/. Accessed 20 December 2019.

19. World Health Organization. Eliminating Malaria. 2016. World Health Geneva, Switzerland. Available from: https://apps.who.int/iris/bitstream/handle/10665/205565/WHO_HTM_GMP_2016.3_eng.pdf. Accessed 7 July 2019

20. Das P, Horton R. Malaria elimination: worthy, challenging, and just possible. Lancet 2010; 376: 1515-7. doi: 10.1016/S01406736(10)61551-6.

21. World Health Organization. World Malaria Report 2008. World Health Organization Geneva, Switzerland. Available online: http://apps.who.int/iris/bitstream/handle/10665/43939/9789241563697_eng.pdf;jsessionid=AD6A336CC77530E82FC28644BA592E7C? sequence=1. Accessed 7 July 2019

22. World Health Organization. World Malaria Report. World 2019. World Health Organization. Geneva, Available online: https://www.mmv.org/sites/default/files/uploads/docs/publications/World\%20Malaria\%20Report_0.pdf. Accessed 7 July 2020

23. Organización Panamericana de la Salud. Actualización Epidemiológica: Malaria en las Américas en el contexto de la pandemia de COVID19. Washington, D.C. OPS/OM. 2020; Pag. 7. Available online: https://www.paho.org/es/documentos/actualizacion-epidemiologicamalaria-10-junio-2020. Accessed 7 July 2019

24. Okumu FO and Moore SJ. Combining indoor residual spraying and insecticide-treated nets for malaria control in Africa: a review of possible outcomes and an outline of suggestions for the future. Malar J. 2011; 10:208. doi: 10.1186/1475-2875-10-208.

25. World Health Organization. World malaria report 2011. World Health Organization. Geneva, Available online: https://www.who.int/malaria/world_malaria_report_2011/WMR2011_noprofiles_lowres.pdf?ua=1. Accessed 14 July 2019

26. Rowland M. Malaria control: bednets or spraying? Malaria control in the Afghan refugee camps of western Pakistan. Trans R Soc Trop Med Hyg. 1999; 93:458-9. doi: 10.1016/s0035-9203(99)90336-x.

27. Pates H, Curtis C. Mosquito behavior and vector control. Ann Rev Entomol. 2005; 50:53-70. doi: 10.1146/annurev.ento.50.071803.130439.

28. Hemingway J, Ranson H. Insecticide resistance in insect vectors of human disease. Ann Rev Entomol. 2000; 45:371-91. doi: 10.1146/annurev.ento.45.1.371.

29. Messenger L, Matias A, Manana AN, Stiles-Ocran JB, Knowles S, Boakye D, et al. Multicentre studies of insecticide-treated durable wall lining in Africa and South-East Asia: entomological efficacy and household acceptability during one year of field use. Malar J. 2012; 11:358. doi: 10.1186/1475-2875-11-358.

30. Ngufor C,Tungu P, Malima R, Kirby M, Kisinza W, Rowland M. Insecticide-treated net wall hangings for malaria vector control: an experimental hut study in north-easternTanzania. Malar J. 2014; 13:366. doi: 10.1186/1475-2875-13-366. 
31. Djènontin A, Chandre F, Dabiré KR, Chabi J, N'Guessan R, Baldet T, et al. Indoor use of plastic sheeting impregnated with carbamato combined with long-lasting insecticidal mosquito nets for the control of pyrethroid-resistant malaria vectors. Am J Trop Med Hyg. 2010; 83:266-70. doi: 10.4269/ajtmh.2010.10-0012.

32. World Health Organization. Guidelines for testing mosquito adulticides for indoor residual spraying and treatment of mosquito nets. 2006. World Health Organization. Geneva, Available online:

https://apps.who.int/iris/bitstream/handle/10665/69296/WHO_CDS_NTD_WHOPES_GCDPP_2006.3_eng.pdf?sequence=1\&isAllowed=y. Accessed 14 October 2019.

33. World Health Organization. Pesticides and their application for the control of vectors and pests of public health importance. 2006. World Health Organization. Geneva, Available online:

https://apps.who.int/iris/bitstream/handle/10665/69223/WHO_CDS_NTD_WHOPES_GCDPP_2006.1_eng.pdf?sequence=1\&isAllowed=y. Accessed 21 December 2019.

34. Anthony N, Rocheleau T, Mocelin G, Lee HJ, ffrench-Constant R. Cloning, sequencing and functional expression of an acetylcholinesterase gene from the yellow fever mosquito Aedesaegypti. FEBS Lett 1995; 368:461-5. doi: 10.1016/0014-5793(95)00711-H. PubMed: 7635199.

35. Akogbéto MC, Padonou GG, Bankole HS, Gazard DK, Gbedjissi GL. Dramatic decrease in malaria transmission after large-scale indoor residual spraying with bendiocarb in Benin, an area of high resistance of Anophelesgambiae to pyrethroids. Am J Trop Med Hyg. 2011; 85:586-93. doi:10.4269/ajtmh.2011.10-0668. PubMed: 21976555.

36. Rowland M, Boko P, Odjo A, Asidi A, Akogbeto M, N'Guessan R. A new long-lasting indoor residual formulation of the organophosphate insecticide pirimiphos methyl for prolonged control of pyrethroid resistant mosquitoes: an experimental hut trial in Benin. PLoS ONE 2013, 8:e69516. doi:69510.61371/journal.pone.0069516.

37. Alou LPA, Koffi AA, Adja MA, Tia E, Kouassi PK, Koné M, et al. Distribution of ace-1R and resistance to carbamates and organophosphates in Anopheles gambiae s.s. populations from Côte d'Ivoire. Malar J 2010; 9:167. doi: 10.1186/1475-2875-9-167.

38. Namountougou M, Simard F, Baldet T, Diabaté A, Ouédraogo J, Martin T, et al. Multiple insecticide resistance in Anopheles gambiae s.l. populations from Burkina Faso, West Africa. PLoS ONE 2012, 11:e48412. https://doi.org/10.1371/journal.pone.0048412.

39. Ngufor C, Chouaïbou M, Tchicaya E, Loukou B, Kesse N, N'Guessan R, et al. Combining organophosphate-treated wall linings and longlasting insecticidal nets fails to provide additional control over long-lasting insecticidal nets alone against multiple insecticideresistantAnopheles gambiae in Côte d'Ivoire: an experimental hut trial. Malar J. 2014; 13:396. doi: 10.1186/1475-2875-13-396.

40. World Health Organization. The Evaluation Process for Vector Control Products. 2018. World Health Organization. Geneva, Available online: https://www.who.int/pq-vector-control/prequalified-lists/who_dec_doc_sumishield50wg.pdf?ua=1. Accessed 14 May 2020

41. AnsariMA, Mittal PK, Razdan RK, Batra CP. Residual efficacy of deltamethrin 2.5 wp (K-othrin) sprayed on different types of surfaces against malaria vector Anopheles culicifacies. Southeast Asian J Trop Med Public Health. 1997; 28:606-9.

42. Rohani A, Zamree I, Mohamad Ali WNW, Hadi AA, Asmad M, Nor ZM, et al. Impact of Indoor Residual-Sprayed Deltamethrin on Different Surfaces in a Malaria Endemic Area in Balai Ringin, Sarawak. Advances in Entomology. 2014; 2:151-60. Doi: 10.4236/ae.2014.23023.

43. Mulambalah CS, Siamba DN, Ngeiywa MM, Vulule, JM. Evaluation of Lamda-Cyhalothrin on Different Surfaces in a Malaria EpidemicProne Area in Kenya. Research Journal of Biological Sciences 2010; 5:258-63. Doi: 10.3923/rjbsci.2010.258.263.

44. Cáceres L, Rovira J, García A, Torres R. Determinación de la resistencia a insecticidas organofosforados, carbamatos y piretroides en Anopheles albimanus (Díptera: Culicidae) de Panamá. Biomédica. 2011; 31: 419-27. doi: http://dx.doi.org/10.7705/biomedica.v31i3.388.

45. Cáceres L, Rovira J, Torres R, García A, Calzada J, De La Cruz M.Caracterización de la transmisión de la malaria por Plasmodium vivax en la región fronteriza de Panamá con Costa Rica en el municipio de Barú, Panamá. Biomédica 2012; 32: 557-69.

doi: http://dx.doi.org/10.7705/biomedica.v32i4.773.

46. Ministerio de Salud. Manual de normas y procedimientos para la malaria. República de Panamá, Ministerio de Salud de Panamá. 2011; 172 pag. Geneva, Available online: http://www.minsa.gob.pa/sites/default/files/publicacion-general/manualnormayprocmalaria.pdf. Accessed 14 November 2020

47. Najera JA,Kouznetsov RL \& Delacollette C. Malaria Epidemics, Detection and Control, Forecasting and Prevention. 1998. World Health Organization. Geneva, Available online: https://apps.who.int/iris/bitstream/handle/10665/64427/WHO_MAL_98.1084.pdf?sequence=1. Accessed 26 January 2020

48. World Health Organization. Manual for indoor residual spraying: Application of residual sprays for vector control. 3rded. 2007. World Health Organization. Geneva, Available online: https://apps.who.int/iris/bitstream/handle/10665/69664/WHO_CDS_NTD_WHOPES_GCDPP_2007.3_eng.pdf?sequence=1\&isAllowed=y. Accessed 19 February 2020

49. World Health Organization. Test procedures for insecticide resistance monitoring in malaria vector mosquitoes. Second edition. 2016. World Health Organization. Geneva, Available online: http://apps.who.int/iris/bitstream/handle/10665/250677/9789241511575-eng.pdf?

Page 10/16 
sequence=1\&isAllowed=y. Accessed 4 September 2019

50. Abbott WS. A method of computing effectiveness of an insecticide. J Eco $n$ Entomol 1925, 18:265-7. https://doi.org/10.1093/jee/18.2.265a

51. Fraire SP. Analysis of the principle problems impeding normal development of malaria eradication programs. Bull Pan Am Health Organ 1975; 9:283-94.

52. Fonseca-Gonzalez I, Quinones ML, McAllister J, Brogdon WG. Mixed-function oxidases and esterases associated with cross-resistance between DDT and lambdacyhalothrin in Anopheles darlingi Root 1926 populations from Colombia. Mem Inst Oswaldo Cruz. 2009; 104:18-26. doi: 10.1590/s0074-02762009000100003.

53. Dzul FA, Penilla RP, Rodríguez AD. Susceptibilidad y mecanismos de resistencia a insecticidas en Anopheles albimanus del sur de la Península de Yucatán, México. Salud Publica Mex.2007; 49:302-11. DOI: 1590/S0036-36342007000400010

54. World Health Organization. Chemical methods for the control of arthropod vectors and Pests of Public Health Importance. G World Health Organization. 1984; 108 pp. World Health Organization. Geneva, Switzerland. Available online: https://apps.who.int/iris/handle/10665/37235. Accessed 4 September 2019

55. World Health Organization. Technical Report Series No. 735, 1986 (WHO Expert Committee on Malaria: eighteenth report. DOI: https://doi.org/10.1017/S0031182000058145.

56. Cáceres L. La lucha antimalárica en Panamá. Primera edición. Panamá: Editorial Poligrafía, S.A.; 1999. p. 63.

57. Cáceres L, Rovira J, Torres R, Calzada JE, Victoria C, Griffith M. Conocimientos, actitudes y practicas sobre la malaria en la población indígena guna de la Comarca de Madungandi. Biomédica. 2015; 35:2386. DOl: https://doi.org/10.7705/biomedica.v35i4.2386.

58. Santos RL, Fayal AS, Aguiar AE, Vieira DB, Póvoa MM. Evaluation of the Residual Effect of Pyrethroids on Anopheles in Brazilian Amazon. Revista de Saúde Pública. 2007; 41:276-83. http://dx.doi.org/10.1590/S0034-89102007000200015.

59. Hadaway AB, Barlow F. Some physical factors affecting the efficiency of insecticides. Trans R Soc Trop Med Hyg. 1952; 46:236-44. doi: 10.1016/0035-9203(52)90071-0.

60. Penna R, Oliveira AE, Ferreira MF, Jonhnson C, Bosworth A, Marsden PD. The influence of building materials on the residual action of BHC. Mem Inst Oswaldo Cruz. 1985; 80: 443-5. doi: 10.1590/s0074-02761985000400010.

61. Yewhalaw D, Balkew M, Shililu J, Suleman S, Getachew A, Ashenbo G, et al. Determination of the residual efcacy of carbamate and organophosphate insecticides used for indoor residual spraying for malaria control in Ethiopia. Malar J. 2017; 16:471 DOI 10.1186/s12936-017-2122-3.

62. World Health Organization. Indoor residual spraying. An operational manual for indoor residual spraying (IRS) for malaria transmission control and elimination. Second Edition. 2015. World Health Organization. Geneva, Available online: http://apps.who.int/iris/bitstream/handle/10665/177242/9789241508940_eng.pdf?sequence=1. Accessed 4 September 2019

63. Etang J, Nwane P, Mbida J, Piameu M, Manga B, Souop D. Variations of insecticide residual bio-efficacy on different types of walls: results from a community-based trial in south Cameroon. Malar J. 2011; 10:1186. doi: 10.1186/1475-2875-10-333.

64. Bradley J, Matias A, Schwabe C, Vargas D, Monti F, Nseng G, et al. Increased risks of malaria due to limited residual life of insecticide and outdoor biting versus protection by combined use of nets and indoor residual spraying on Bioko Island, Equatorial Guinea. Malar J. 2012; 11:242. doi: 10.1186/1475-2875-11-242.

65. Sherrard-Smith E, Griffin JT, Winskill P, Corbel V, Pennetier C, Djénontin A, et al. Systematic review of indoor residual spray efficacy and effectiveness against against Plasmodium falciparum in Africa. Nat Commun. 2018; 26;9(1):4982. doi: 10.1038/s41467-018-07357-W.

66. Dengela D, Seyoum A, Lucas B, Johns B, George K, Belemvire A, et al. Multi-countryassessment of residual bioefficacy of insecticides used for indoor residual spraying in malaria control on different surface types: results from program monitoring in17PMI/USAID-supported IRS countries. Parasit Vectors. 2018; 30;11(1):71. doi: 10.1186/s13071017-2608-4.

67. World Health Organization. WHO recommended insecticides for indoor residual spraying against malaria vectors. 2013. World Health Organization. Geneva, Available online: http://www.who.int/whopes/Insecticides_IRS_Malaria_25_Oct_2013.pdf. Accessed 4 September 2019

68. Giardina F, Kasasa S, Sié A, Utzinger J, Tanner M, Vounatsou P. Effects of control-vectors interventions in risk of malaria parasitaemia in sub-Saharan Africa: a spatial and temporal analysis. Lancet Glob Health.2014; 2(10):e601-15. doi: 10.1016/S2214-109X(14)70300-6.

69. Churcher TS, Lissenden N, Griffin JT, Worrall E, Ranson H. The impact of pyrethroid resistance on the efficacy and effectiveness of bednets for malaria control in Africa. Elife. 2016; 5:e16090. https://doi.org/ 10.7554/eLife.16090 
70. Calzada JE, Marquez R, Rigg C, Victoria C, De La Cruz M, Chaves LF, et al. Characterization of a recent malaria outbreak in the autonomous indigenous region of Guna Yala, Panama. Malar J. 2015; 14:459. DOI 10.1186/s12936-015-0987-6.

71. Ekoko WE, Awono-Ambene P, Bigoga J, Mandeng S, Piameu M, Nvondo N, et al.Patterns of anopheline feeding/resting behaviour and Plasmodium infections in North Cameroon, 2011-2014: implications for malaria control. Parasites Vectors. 2019; 12, https://doi.org/10.1186/s13071-019-3552-2

72. Gatton ML, Chitnis N, Churcher T, Donnelly MJ, Ghani AC, Godfray HCJ, et al. The importance of mosquito behavioural adaptations to malaria control in Africa. Evolution 2013; 67:1218-30. doi: 10.1111/evo.12063.

73. Sokhna C, Ndiath MO, Rogier $\mathbf{C}$. The changes in mosquito vector behavior and the emerging resistance to insecticides will challenge the decline of malaria. Clin Microbiol Infect. 2013; 19:902-7. doi: 10.1111/1469-0691.12314.

74. Rodríguez AD, Penilla RP, Rodríguez MH, Hemingway J, Trejo A, Hernández-Avila JE. Acceptability and perceived side effects of insecticide indoor residual spraying under different resistance management strategies.Salud Pública Mex. 2006; 48:317-24. doi: 10.1590/s003636342006000400006 .

\section{Tables}

Table 1 Geographical and epidemiological information of all locations where the studies on fenitrothion bio-efficacy against Anopheles (Nys.) albimanus were conducted.*

\begin{tabular}{|c|c|c|c|c|c|c|}
\hline Province/Comarca & Community & $\begin{array}{l}\text { Geographical } \\
\text { coordinates }\end{array}$ & Altitude & No. houses & Inhabitants & $\begin{array}{l}\text { Malaria cumulative cases } \\
2015-2017^{\star}\end{array}$ \\
\hline **Ngäbe-Bugle & Quebrada Peña & $\begin{array}{l}8^{0} 45^{\prime} 47.40^{\prime \prime} \mathrm{O} \\
81^{0} 23^{\prime} 38.75^{\prime \prime} \mathrm{N}\end{array}$ & $19 \mathrm{~m}$ & 18 & 185 & 15 \\
\hline 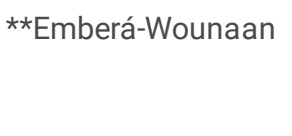 & Bajo Chiquito & $\begin{array}{l}8^{0} 2818.76^{\prime \prime} \mathrm{N} \\
77^{0} 41^{\prime} 26.95^{\prime \prime} \mathrm{O}\end{array}$ & $50 \mathrm{~m}$ & 48 & 180 & 37 \\
\hline$\star *$ Madungandi & Ipeti Guna & $\begin{array}{l}8^{0} 54^{\prime} 26.22^{\prime \prime} \mathrm{N} \\
78^{0} 12^{\prime} 05.8^{\prime \prime} \mathrm{O}\end{array}$ & $122 \mathrm{~m}$ & & & 13 \\
\hline$\star \star$ Wargandi & Morti & $\begin{array}{l}8^{0} 51^{\prime} 14.56^{\prime \prime} \mathrm{N} \\
77^{0} 55^{\prime} 39.29^{\prime \prime} \mathrm{O}\end{array}$ & $65 \mathrm{~m}$ & 80 & 395 & 42 \\
\hline Darién & Bella Vista & $\begin{array}{l}8^{0} 09^{\prime} 27.86^{\prime \prime} \mathrm{N} \\
77^{0} 31^{\prime} 51.56^{\prime \prime} \mathrm{O}\end{array}$ & $13 \mathrm{~m}$ & 99 & 200 & 15 \\
\hline Bocas del Toro & Barranco Afuera & $\begin{array}{l}9^{0} 09^{\prime} 27.86^{\prime \prime} \mathrm{N} \\
82^{0} 43^{\prime} 13.99^{\prime \prime} \mathrm{O}\end{array}$ & $13 \mathrm{~m}$ & 300 & 1500 & 9 \\
\hline
\end{tabular}

*Data provided by NMP. **Indigenous comarca.

Due to technical limitations, table 2 is only available as a download in the Supplemental Files section.

Table 3 Insecticide susceptibility in adult field-derived Anopheles (Nys.) albimanus mosquitoes Aguas Claras strain, Panama. 


\begin{tabular}{|lllll|}
\hline & No. of exposed mosquitoes & No. dead at 24 h post-exposure & $\% \pm 95 \% \mathrm{Cl}$ & Susceptibility \\
\hline Insecticide & 500 & 492 & $98.4(97.3 \pm 99.5)$ & Susceptible \\
\hline Malathion (5\%) & 500 & 489 & $97.8(96.5 \pm 99.1)$ & Susceptible \\
\hline Pirimiphos-methyl (0.25\%) & 500 & 475 & $95.0(93.1 \pm 96.9)$ & Resistant \\
\hline Chlorpyrifos (0.4\%) & 500 & 465 & $93.0(90.8 \pm 95.3)$ & Resistant \\
\hline Propoxur $(0.1 \%)$ & 500 & & & \\
\hline
\end{tabular}

$(\%)^{\star}$ The percent mortality is expressed as medians.

\section{Figures}

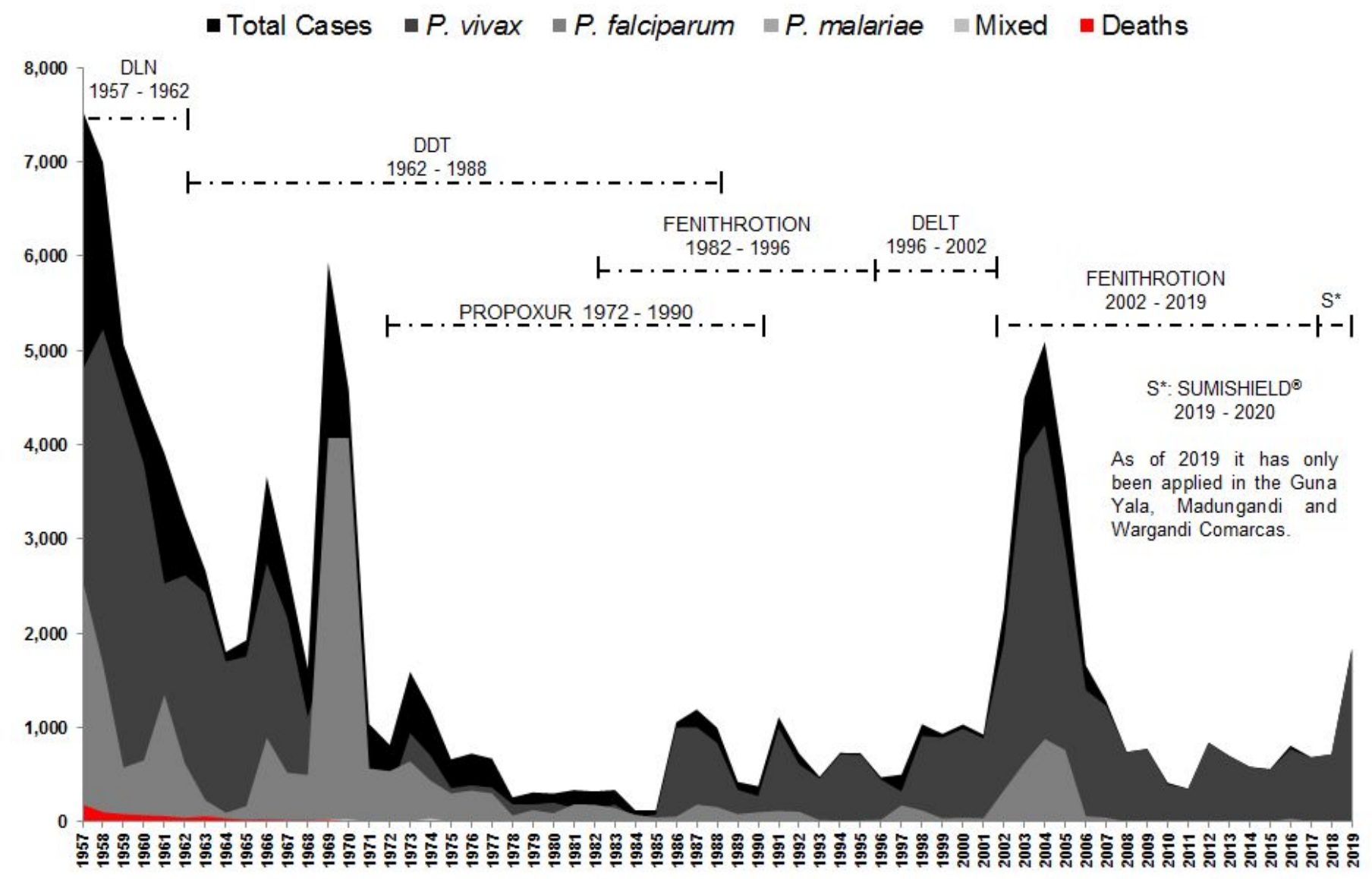

Figure 1

Epidemiological behavior of malaria and application of residual action insecticides against anopheline vectors in Panama, 1957 -2019. 


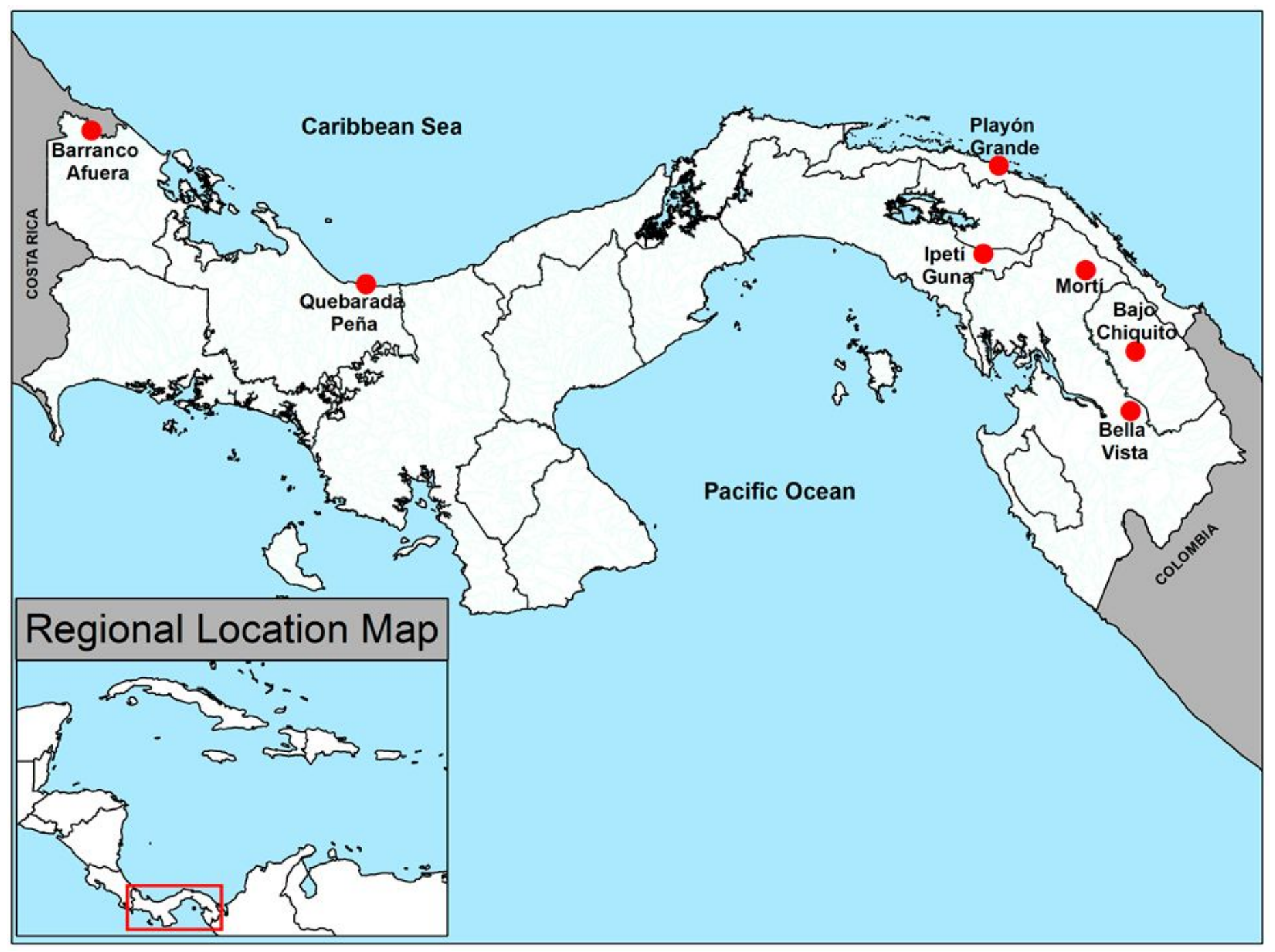

Figure 2

Geographical location of all the selected communities for the assessment of fenitrothion bio-efficacy against Anopheles (Nys.) albimanus in Panama. 

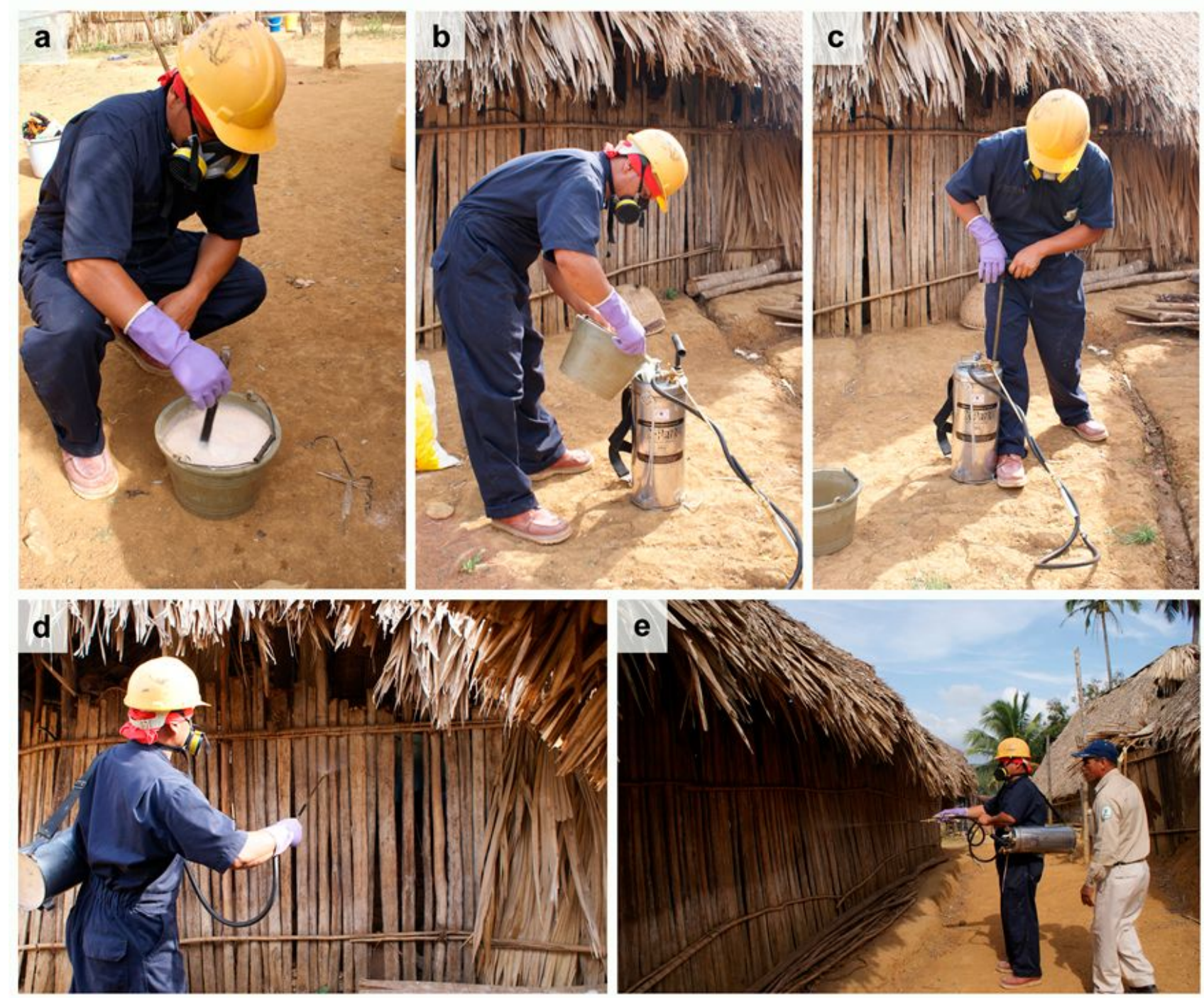

Figure 3

Fenitrothion application (a) Insecticide formulation with water (b) Sprinkler loading and preparation (c) Pressure application to the sprinkler system (d) IRS application (e) IRS application supervision by the brigade chief.
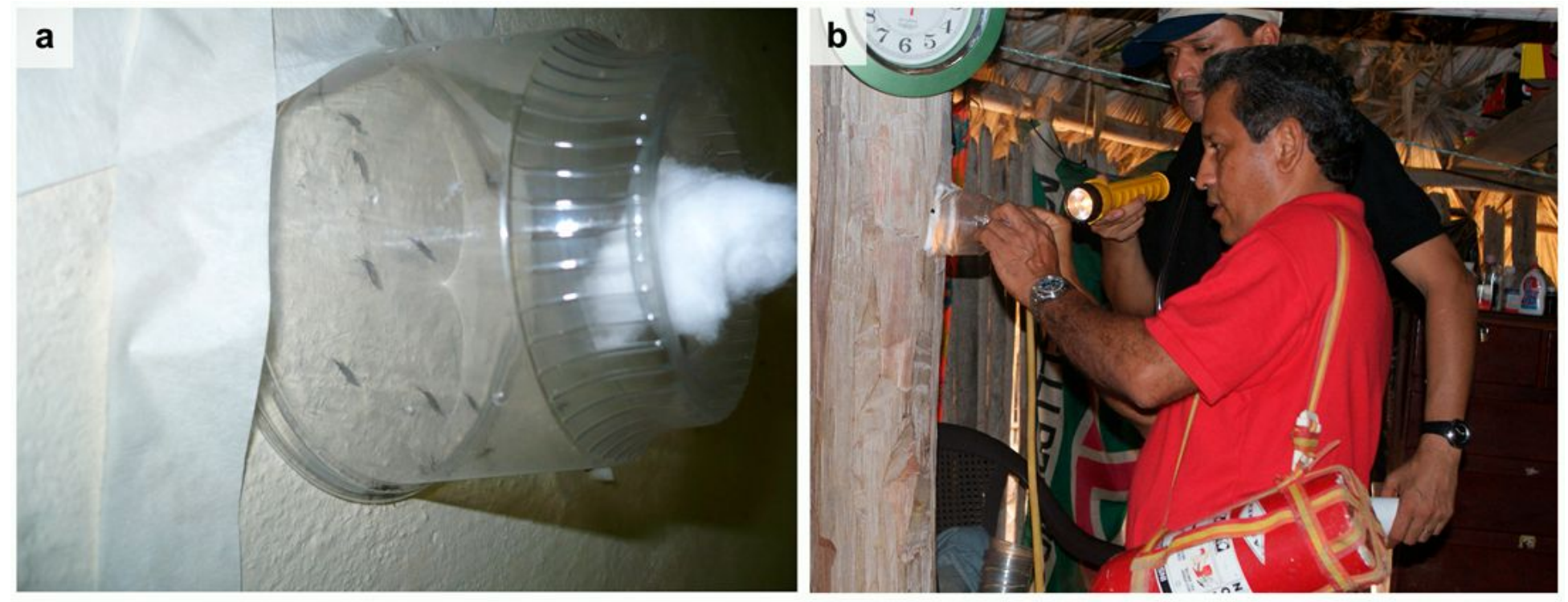


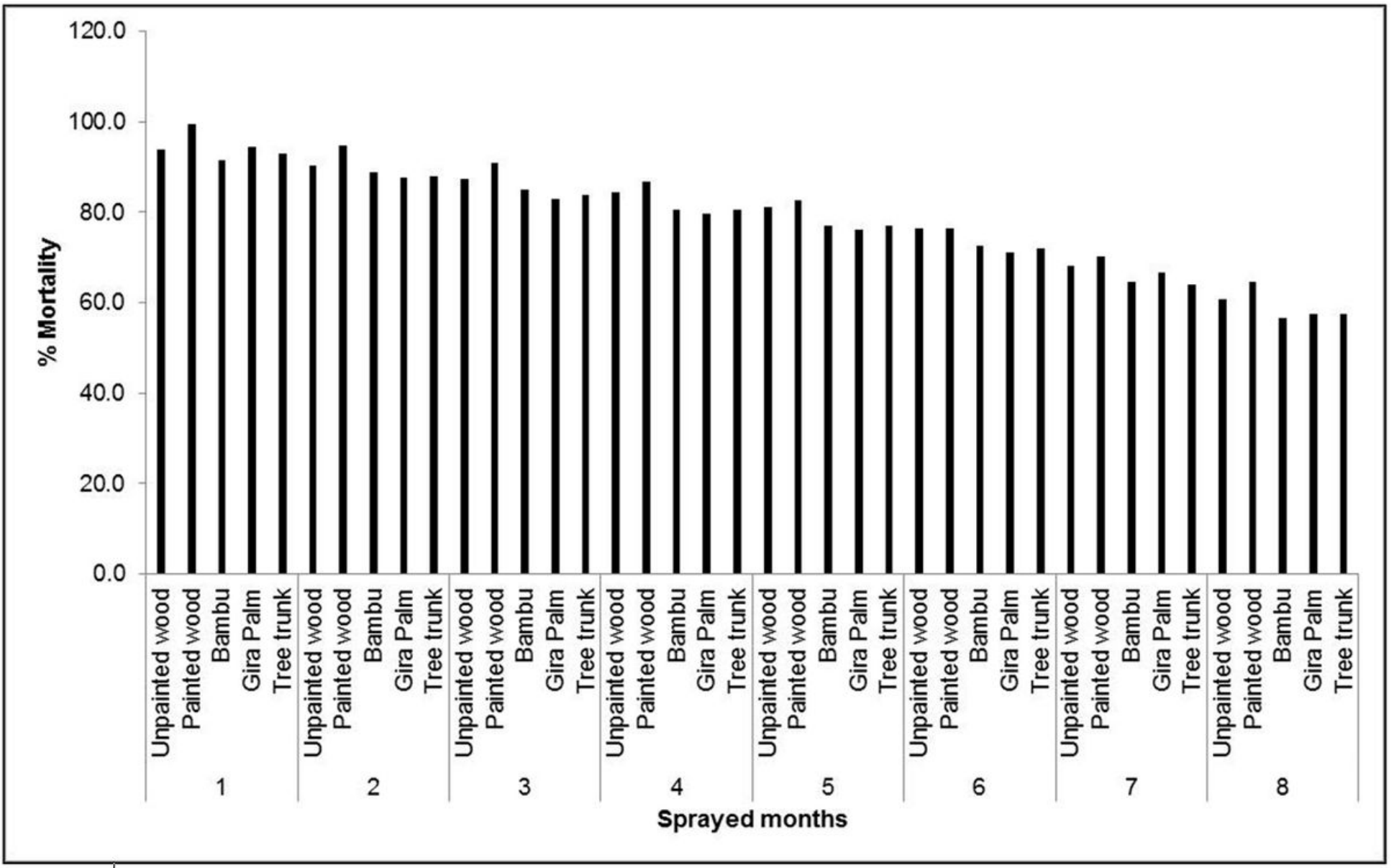

Figure 5

Percent mortality of Anopheles (Nys.) albimanus exposed to different intradomicile surface types treated with the insecticide fenitrothion.

\section{Supplementary Files}

This is a list of supplementary files associated with this preprint. Click to download.

- BioefficacyfenithrotionagaintAn.albimanusPanama.pdf

- Table2.jpg 